\title{
Influence of well management in the development of multiple reservoir sharing production facilities
}

\author{
João Carlos von Hohendorff Filho* and Denis José Schiozer \\ University of Campinas, UNICAMP, PO Box 6052, Campinas, CEP 13083-970 São Paulo, Brazil
}

Received: 27 May 2020 / Accepted: 10 August 2020

\begin{abstract}
Well prioritization rules on integrated production models are required for the interaction between reservoirs and restricted production systems, thus predicting the behavior of multiple reservoir sharing facilities. This study verified the impact of well management with an economic evaluation based on the distinct prioritizations by reservoir with different fluids. We described the impact of the well management method in a field development project using a consolidated methodology for production strategy optimization. We used a benchmark case based on two offshore fields, a light oil carbonate and a black-oil sandstone, with gas production constraint in the platform. The independent reservoir models were tested on three different approaches for platform production sharing: (Approach 1) fixed apportionment of platform production and injection, (Approach 2) dynamic flow-based apportionment, and (Approach 3) dynamic flow-based apportionment, including economic differences using weights for each reservoir. Approach 1 provided the intermediate NPV compared with the other approaches. On the other hand, it provided the lowest oil recovery. We observed that the exclusion of several wells in the light oil field led to a good valuation of the project, despite these wells producing a fluid with higher value. Approach 2 provided the lower NPV performance and intermediate oil recovery. We found that the well prioritization based on flow failed to capture the effects related to the different valuation of the fluids produced by the two reservoirs. Approach 3, which handled the type of fluids similarly to Approach 1, provided a greater NPV and oil recovery than the other approaches. The weight for each reservoir applied to well prioritization better captured the gains related to different valuation of the fluids produced by the two reservoirs. Dynamic prioritization with weights performed better results than fixed apportionment to shared platform capacities. We obtained different improvements in the project development optimization due to the anticipation of financial returns and CAPEX changes, due mainly from adequate well apportionment by different management algorithm. Well management algorithms implemented in traditional simulators are not developed to prioritize different reservoir wells separately, especially if there are different economic conditions exemplified here by a different valuation of produced fluids. This valuation should be taken into account in the short term optimization for wells.
\end{abstract}

$\begin{array}{ll}\text { Nomenclatures and Abbreviations } \\ \text { CAPEX } & \text { CAPital EXpenditures } \\ \text { CV } & \text { Coefficient of Variation } \\ \text { dNPV } & \text { Gain relative to the previous NPV } \\ \text { EMV } & \text { Expected Monetary Value } \\ \text { FL } & \text { Diameter of production/injection line } \\ \text { G1 } & \text { Project and implementation variables } \\ \text { G2 } & \text { Variables of production control } \\ \text { G3 } & \text { Variables of project change } \\ \text { GOR } & \text { Gas-Oil Ratio } \\ G_{p} & \text { Cumulative gas production }\end{array}$

* Corresponding author: hohendorff@cepetro. unicamp. br
IDLHC Iterative Discrete Latin Hypercube

Sampling

IOR Improved Oil Recovery

$N_{p} \quad$ Cumulative oil production

NPV Net Present Value

OPEX OPerating EXpenses

$\mathrm{PC} \quad$ Diameter of the production/injection column

QLIFT Gas lift injection rate for well

$Q_{\mathrm{o}}, Q_{\mathrm{g}}, \quad$ Limits of platform flow rate for oil, gas, water

$Q_{\mathrm{w}}, Q_{1} \quad$ and liquid production

$Q_{\text {wi }} \quad$ Limit of platform flow rate for water injection

RI Diameter of riser

$W_{i} \quad$ Cumulative water injection

$W_{p} \quad$ Cumulative water production 


\section{Introduction}

The current Brazilian productive and economic oil \& gas scenario poses enormous challenges, with discoveries of carbonate reservoirs in ultra-deep waters that are very distant from the coast, overlapped reservoirs with distinct characteristics, and the growing need to optimize offshore production systems and share limited infrastructure for different projects [1].

An important work [2] stated that the South Atlantic accounts for roughly $7 \%$ of the world's hydrocarbon reserves, contained in a belt of deposits along the coasts of West Africa and on eastern seaboard of the South American continent (mostly in Brazil). This can be explained by the multiplicity of the petroleum systems (source rocks, reservoir rocks, cap-rocks, and traps).

The main contributors to an integrated reservoir management are: well design and management, reservoir characterization, reservoir modeling, surface facilities design, and economics. The integration of these items enables one to propose and design efficient and economic ways of producing reservoirs, adding value to companies' assets [3].

Some authors [4] proposed a workflow that can generate and manage multiple realizations, which in turn promotes robust and realistic estimates of uncertainties in in-situ and produced volumes. It is also used for risk mitigation and decision support, for example: to evaluate the robustness of well placement, well number, top side capacities, etc.

The integration of reservoir and production systems is a recommended best practice, especially for projects involving large capital investments because it provides a more stringent (technical and economical) project assurance, and it is also required by the latest subsea processing technologies. The effort to integrate these models in order to optimize overall system performance presents many technological challenges [5].

Several recent methodologies $[6-8]$ have tried to improve coupling reservoir models and production system models to simulate integrated solutions, representing fluid flow through the reservoir to the surface, more accurately.

Well prioritization rules on integrated production models are required for interaction between reservoirs and restricted production systems, predicting the behavior of multiple reservoir sharing facilities.

There are defined groups of variables to be studied in research and development projects: group G1, which includes project and implementation variables; group G2, which includes the variables of production control; and group G3, which involves the variables of project change (revitalization) [9].

Some authors [10] concluded that the control of G2 exerts a greater influence on the economic return depending on the situation where it is employed. This result serves as the basis for deciding, in future work, when it is necessary to perform a more thorough analysis of group G2. However, in the cases studied, the authors observed that the EMV and NPV were increased without additional expenses, evidencing that it can be useful to optimize G2 at some point in the life of the field.
Short-term (G2) optimization, which also aims for longterm optimization, can render benefits to both periods analyzed. The paper authors commented that many articles in the literature mention the benefits of short-term optimization, but fail to consider the long-term effects. They demonstrated that we can increase oil production, both in the short- and long-term, therefore maximizing the NPV of the field [11].

A study [12] presented an efficient production optimization scheme for an oil reservoir with water injection by optimizing the production rate for each well (group G2), using an adaptive version of simulated annealing in two steps. The results showed improved flow rates which optimized the total oil production.

Some researchers [13] presented a study to better understand and optimize management and operation (group G2) in a carbonate field. The paper authors developed a numerical reservoir model through matching production and pressure data and then investigated the impact of water flooding injection rate, injection locations, and timing of injection to finally develop optimized Improved Oil Recovery (IOR) methods based on ultimate oil recovery and economics.

For production poles, a frequent operational limitation is gas flow since, depending on the specifications for environmental protection; the burning option has become restrictive. In this context, it is common for many fields to share the same gas flow system. The paper authors demonstrated that the gas flow limit is an operational restriction that influences the selection of the production strategy and, the lower the gas capacity, the greater its influence on the production strategy [14].

For a case they studied that was subject to gas production limitation - the apportionment allocation rule, which prioritizes the restriction of wells with higher GOR (GasOil Ratio) - provided higher profitability to the project, evidencing the need to study the definition of the best reservoir management strategy on a case-by-case basis. However, the paper authors applied the same economic model for all the fluids [15].

A study [16] revealed a small gain through the application of different strategies for the allocation of a well's flow rate, prioritizing the restriction of wells according to selected parameters. For the case studied, where there is a great difference between the GOR of the reservoirs and the impact of the gas restriction is noticeably high in the production of light oil, the strategy that prioritizes the restriction of wells with higher instantaneous gas flow is the most profitable. Again, the instant gas flow rule seems to be the most appropriate well management rule, but it does not take into account the type of oil being produced (and its corresponding valuation). GOR control was not effective in handling this valuation.

The paper authors also commented that for coupling reservoirs and production system in order to maintain the detailed characterization of each reservoir in separate simulation models and testing integrated management alternatives, which could optimize the results of shared production, one option is to use the explicit coupling between 
the models through an external tool that controls well group management.

\section{Objective}

The objective of this study is to verify the impact of well management in field development using an economic evaluation based on the distinct prioritizations by reservoir, with different fluids.

\section{Methodology}

To evaluate the impact of the well management, we first assessed development decision changes for the production phase comparing design parameters, control parameters, and performance results from an optimized production strategy for a representative model. This concept is common in decision-making processes based on models as it avoids poor choices leading to incorrect conclusions.

We describe the impact of the well management method in a field development project using a consolidated methodology for production strategy optimization $[9,17]$.

The optimization problem was modified to include new design and control variables for production systems. The infrastructure design comprises the number, length and position of wells, well opening schedule, and platform flow-rate limits. We also included the platform location, geometrical and operational characteristics of wells and gathering systems.

We expanded the assisted optimization workflow [17] to clarify the methodology. After optimization processes without integration [9], we define a step for production system integration with reservoir. We define initial guesses for platform position, pipe diameters and artificial lift method, and define optimization steps of these variables in isolated processes, as shown in Figure 1.

The assisted optimization without integration begins with an initial estimate of the number and location of wells, limits of platform flow rates, and the well opening schedule. The optimization process follows a particular order based on the importance of each expected design variable. But as some specific questions about well and gathering systems optimization remain, we define other start points and conditions for the assisted optimization with integration, as initial guess of pipe diameters and operational constraint assumptions.

We use an integrated model case based on two reservoirs with different stream oils, with production and injection constraints in the shared platform. The independent reservoir models are tested on three different well management approaches for platform production sharing, evaluating their impact in field development.

Approach 1 uses fixed apportionment of platform production and injection capacities, common to integrate multiple reservoirs in separate simulations [14, 15, 17]. We apply static percentages for production and injection capacities for each reservoir separately.

Approach 2 uses dynamic flow-based apportionment, common in joint integrated simulations [15]. We use
WellPrior methodology [15], with the addition of a term in the denominator to allow for more case studies, with a differentiated form in the treatment of wells that exceed the rate flow, as shown in equation (1). This methodology is applicable for each fluid phase [16],

$$
\begin{aligned}
& \mathrm{WP}= \\
& \left(\frac{A 1 \times Q_{\mathrm{o}}+A 2 \times Q_{\mathrm{g}}+A 3 \times Q_{\mathrm{w}}+A 4 \times P_{\mathrm{bl}}+A 5 \times P_{\mathrm{wf}}}{B 1 \times Q_{\mathrm{o}}+B 2 \times Q_{\mathrm{g}}+B 3 \times Q_{\mathrm{w}}+B 4 \times P_{\mathrm{bl}}+B 5 \times P_{\mathrm{wf}}+B 6}\right)^{N},
\end{aligned}
$$

where WP is well apportionment factor. $A(i), B(i), i=$ $(1,2,3,4,5)$ : interaction coefficients defined by user. $N$ is priority amplification/attenuation factor. $B 6$ is an independent term. $P_{\mathrm{bl}}$ is well block pressure. $P_{\mathrm{wf}}$ is well bottom-hole pressure. $Q_{\mathrm{o}}, Q_{\mathrm{g}}$ and $Q_{\mathrm{w}}$ are oil, gas and water flow rates produced/injected by well, respectively.

The choice of WellPrior coefficients defines the quantities that will be used in the prioritization of wells and, for each type of platform restriction, the use of adequate values of these parameters leads to increased flow rates of the fluid of higher economic value. This method affects all wells of a group equally.

Approach 3 uses a modified dynamic flow-based apportionment, including economic differences, using weights for each reservoir as a specific case for joint integrated simulations. We propose percentage multiplier weight for the WellPrior value calculation, applied to all wells for each reservoir. With this method, we try to incorporate the effect of different economic values of oil streams.

To enable a comparison between approaches, we perform a deterministic optimization using robust software to evaluate the impact of well management in field development using a benchmark case. To calculate the objective function, NPV, the equations and parameters remain similar to a previous work [18]. The objective function considers net cash flow over a field lifetime. In this project, the net cash flow for each period may be calculated based on the Brazilian R\&T fiscal regime considering gross revenues from oil and gas sales, total amount paid in royalties charged over gross revenue, total amount paid in special taxes on gross revenue, operational production costs associated to the oil and water production and water injection, corporate tax rate, investments on equipment and facilities and abandonment cost.

We compare these variables for all optimized strategies: (1) design parameters such as the number and position of wells and geometrical characteristics of well and gathering systems; (2) control parameters such as gas injection rates for artificial lift gas method; and (3) performance results such as Net Present Value (NPV), cumulative oil production $\left(N_{p}\right)$, cumulative water production $\left(W_{p}\right)$, and cumulative water injection $\left(W_{i}\right)$.

\section{Application}

The benchmark UNISIM-I\&II consists of two reservoir models, which in turn are based on the benchmark cases 


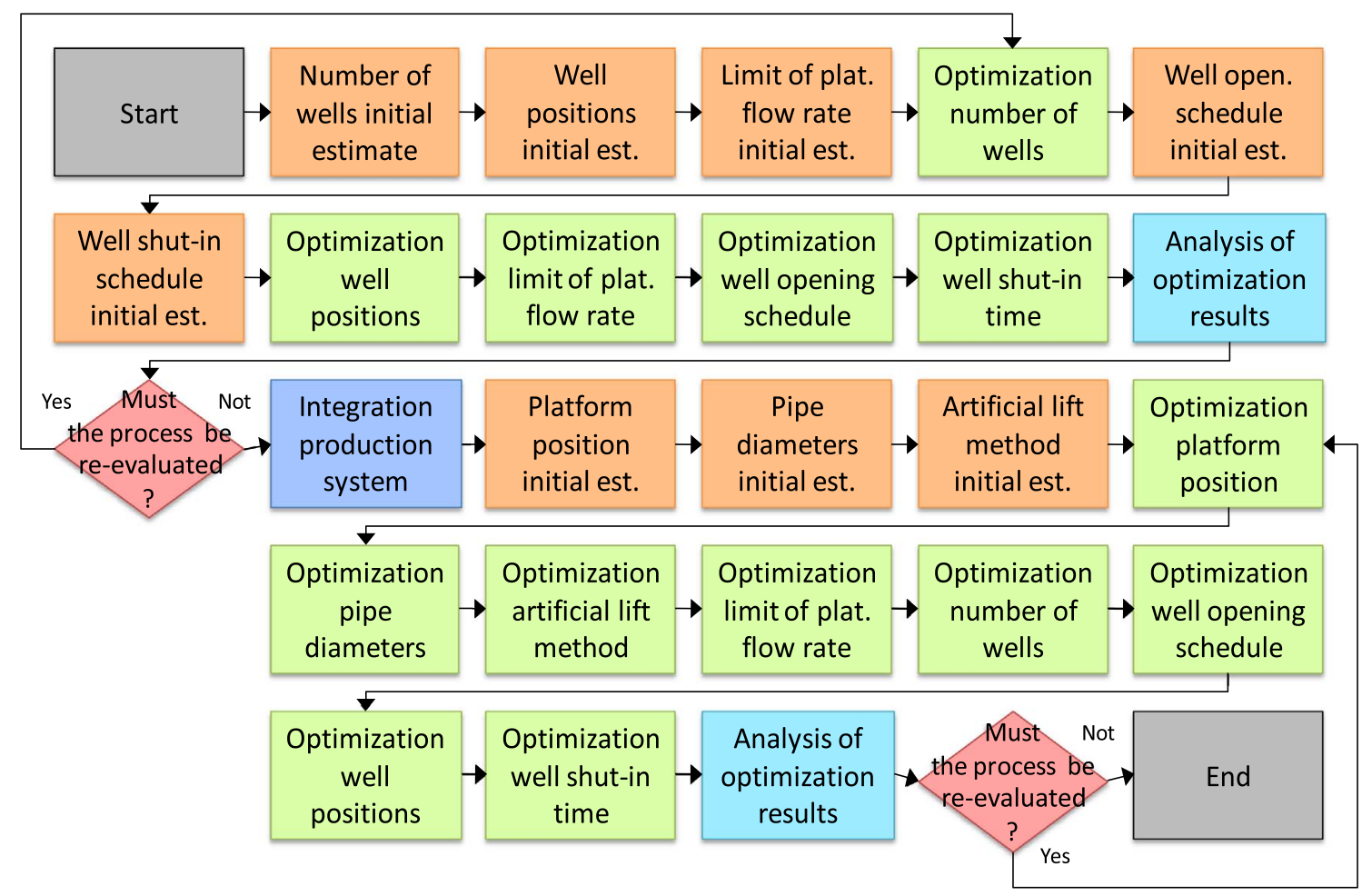

Fig. 1. Optimization workflow for the defined problem (adapted from [17]).

UNISIM-I [18, 19] and UNISIM-II [20], already published separately, and a production system model $[18,21]$. The dataset includes reservoir simulation models, data related to the production system model, and the adopted economic scenario.

The integrated base case was composed by the Arenito sandstone reservoir from UNISIM-I-D, using the representative model RM6 and optimized production strategy E9 [22] with 9 producer wells and 4 injector wells, and the Carbonato carbonate reservoir from UNISIM-II-D, using image 80 [20] with a previously optimized production strategy with 12 producers and 8 vertical injectors in seven-spot pattern. Figure 2 shows initial well locations for the Arenito and Carbonato production strategy. We used conventional black oil simulator IMEX ${ }^{\top \mathrm{M}} 2016$ (CMG) for reservoir simulations.

The base case contained an integrated economic model with reservoir-separated NPV calculation. Waterflooding was selected as the recovery method applicable for both reservoirs. The predefined production system adopted a platform with predetermined location $(X=355400 \mathrm{~m}$, $Y=7516700 \mathrm{~m})$ and highest possible capacity of $180000 \mathrm{bpd}\left(28617 \mathrm{~m}^{3} \mathrm{std} /\right.$ day for oil and liquid production, $19078 \mathrm{~m}^{3} \mathrm{std} /$ day for water production, $38156 \mathrm{~m}^{3} \mathrm{std} /$ day for water injection and 4 million $\mathrm{m}^{3}$ std/day for natural gas production) and slot capacity for 32 wells. The well and gathering system for each well is composed of riser (initial diameter $\mathrm{RI}=6^{\prime \prime}$ ), flowline (initial diameter $\mathrm{FL}=6^{\prime \prime}$ ), and production/injection column (initial diameter $\mathrm{PC}=4^{\prime \prime}$ ) without gas-lift artificial method. Standing fluid correlations
[23] and pressure drop in pipes from Brill and Beggs [24] were used. These correlations were included in the multiphase flow simulator PTUBE 2016 (CMG).

Several optimization methods have been proposed for waterflooding optimization $[25,26]$ and gas lift allocation $[21,27]$. We used sequential optimization method with integration [17] to evaluate the best project variables, as stated. We considered the stop criterion in sequential optimization method when has not increased in the objective function during a complete cycle.

A most notable example is well location, which involves reservoir completion and length of risers, flow lines and production/injection columns. A great effort is demanded in this optimization step and several researchers [26, 28-30] have evaluated methods to reduce the computational cost. IDLHC population method [31] was used for the well location optimization step with a large number of variables (sample size $=20$, iterations $=8$, threshold cut percentage $=0.8$ and valid sample rate $=4)$. In addition, a direct search method was used for steps with few combinations for project variables, as reservoir ratio and weight for WellPrior $(0 \%, 10 \%, 20 \%, 30 \%, 40 \%, 50 \%, 60 \%, 70 \%, 80 \%, 90 \%$, $100 \%)$, pipe diameters $\left(\mathrm{RI}=4^{\prime \prime} / 6^{\prime \prime} / 8^{\prime \prime}, \mathrm{FL}=4^{\prime \prime} / 6^{\prime \prime} / 8^{\prime \prime}\right.$, $\left.\mathrm{PC}=3^{\prime \prime} / 4^{\prime \prime} / 5^{\prime \prime}\right)$, and artificial lift method for producers (without gas lift method, gas lift method with gas injection of $100000 \mathrm{~m}^{3} \mathrm{std} /$ day, gas lift method with gas injection of $200000 \mathrm{~m}^{3} \mathrm{std} /$ day). For optimization of the well number, the evaluation of economic performance for each individual well was analyzed with the equations presented in Gaspar et al. [9] and bad wells were eliminated. 

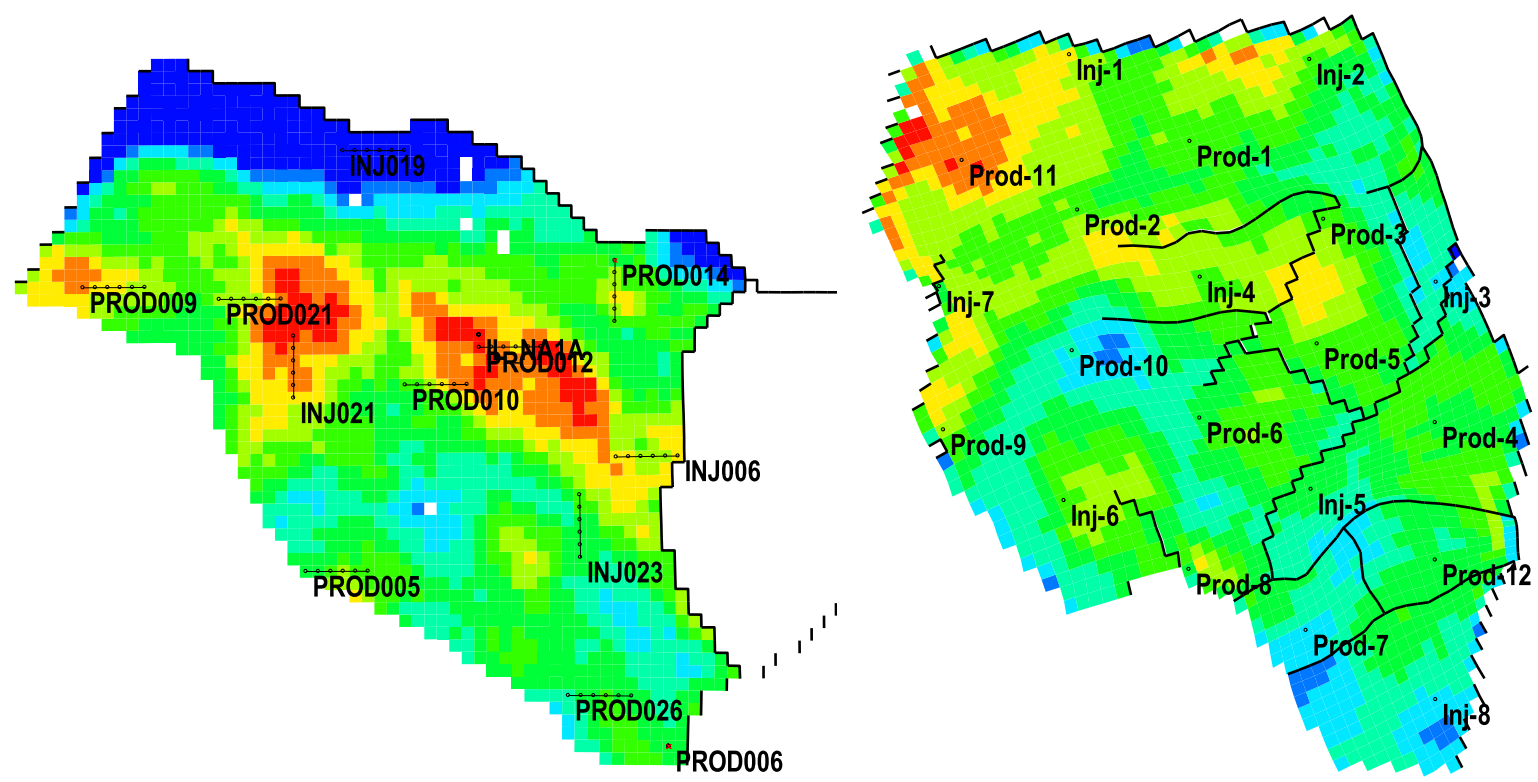

Fig. 2. Initial well locations for the Arenito and Carbonato production strategy.

Table 1. Results obtained during the optimization procedures for Approach 1.

\begin{tabular}{|c|c|c|c|c|}
\hline Step & Optimization & Results & Sims & $\mathrm{dNPV}(\%)$ \\
\hline 1 & Reservoir ratio & $40 \% Q_{\mathrm{o}}, Q_{\mathrm{l}}, Q_{\mathrm{g}}, Q_{\mathrm{w}}, 50 \% Q_{\mathrm{wi}}$ (Arenito) & 7 & 13.1 \\
\hline 2 & Pipe diameter/gas lift & RI:6", FL:6", PC:5", QLIFT $=100000 \mathrm{~m}^{3} /$ day & 8 & 2.2 \\
\hline 3 & Well number & Remove 9 wells (2 Arenito; 7 Carbonato) & 11 & 3.3 \\
\hline 4 & Well placement & 8 iterations & 104 & 3.7 \\
\hline 5 & Reservoir ratio (2nd) & 40\% Qo, Ql, Qg, Qw, 40\% Qwi (Arenito) & 4 & 0.1 \\
\hline 6 & Pipe diameter/gas lift (2nd) & RI:6", FL:6", PC:5", QLIFT $=200000 \mathrm{~m}^{3} /$ day & 1 & 0.2 \\
\hline 7 & Well number (2nd) & Remove 1 well (Carbonato) & 11 & 0.0 \\
\hline 8 & Well placement (2nd) & 8 iterations & 86 & 0.5 \\
\hline
\end{tabular}

Decoupled coupling method [14] was used to integrate the reservoir and production system for Approach 1. For Approach 1, VLP tables were previously generated using multiphase flow simulator. Explicit coupling method [32] was used to integrate the reservoir and production system for Approaches 2 and 3. We used own explicit coupler that generated VLP tables during integrated simulation using multiphase flow simulator.

For all approaches, project variable (G1) optimization steps were: well and gathering system diameters and gas lift configuration, well number and well location. For Approach 1, the initial 50/50\% reservoir ratio was optimized. For Approach 3, percentage weights for reservoirs were optimized.

For Approach 1, operational parameters (G2) for production strategy were ruled by internal well management routine. For Approaches 2 and 3, G2 were ruled by internal coupler routine (WellPrior based) configured equally for the reservoir simulator routine.

\section{Results}

Table 1 summarizes the results obtained during the optimization procedures for Approach 1. dNPV indicates the gain relative to the previous step. The optimization consumed 232 simulations and increased the base case NPV by $25 \%$. Figure 3 shows the evolution of the NPV with the optimization procedure for Approach 1 . The results indicate that there was a $40 \%$ apportionment of platform capacity, which was maintained as a constant throughout the entire forecast production time, for the Arenito reservoir, and that 10 wells were removed.

Figures 4-7 show oil, water, liquid, and gas production for the Arenito and Carbonato reservoirs, as well as total field production, respectively. Figure 8 shows water injection for the Arenito and Carbonato reservoirs, as well as total field injection. Due to the fixed apportionment for each reservoir, there were rate restrictions for oil and gas production in both reservoirs and liquid production 
6 J.C. von Hohendorff Filho and D.J. Schiozer: Oil \& Gas Science and Technology - Rev. IFP Energies nouvelles 75, 70 (2020)

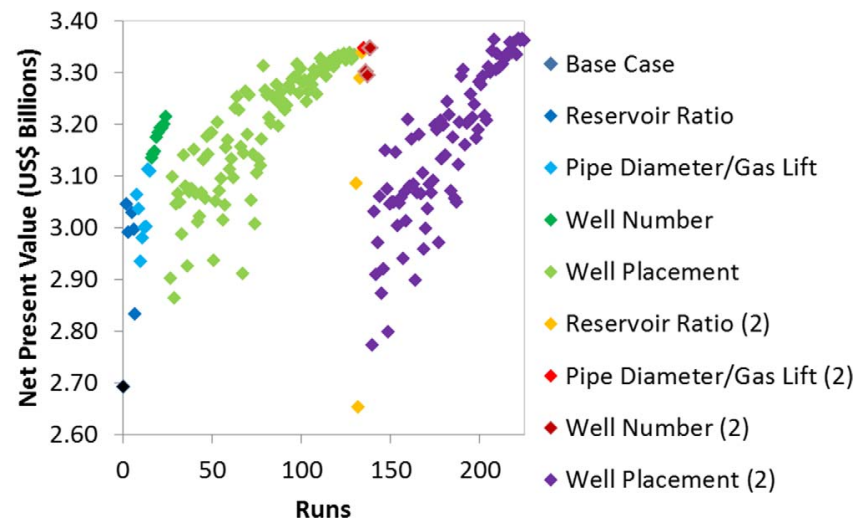

Fig. 3. Evolution of the NPV with the optimization procedure for Approach 1.

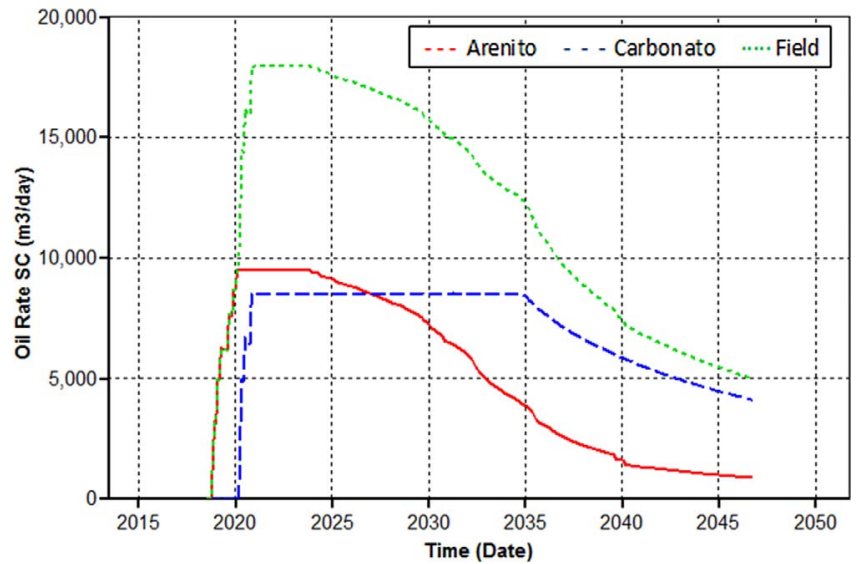

Fig. 4. Oil production for the Arenito and Carbonato reservoirs, and field for Approach 1.

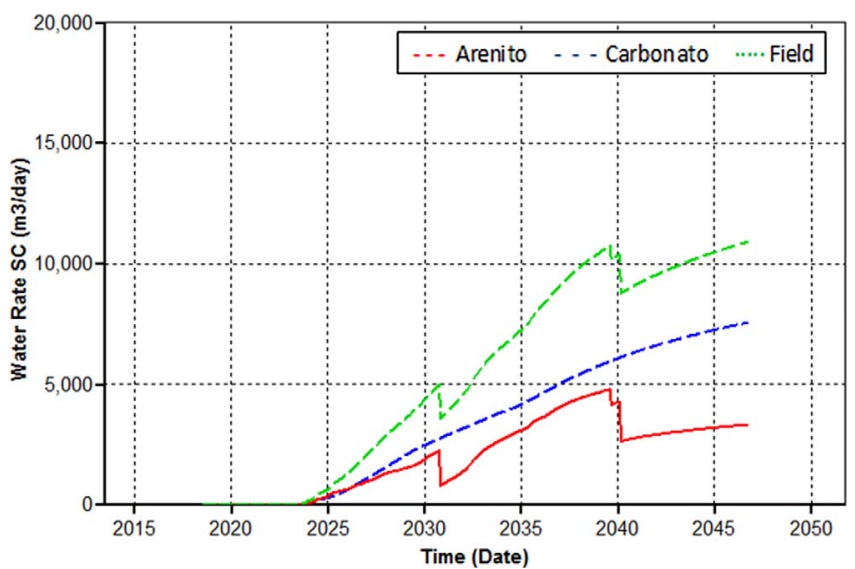

Fig. 5. Water production for the Arenito and Carbonato reservoirs, and field for Approach 1.

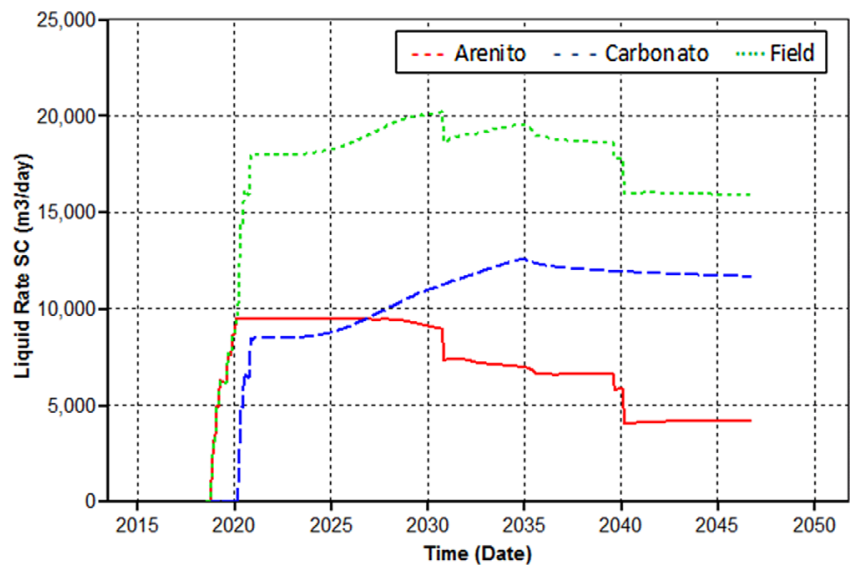

Fig. 6. Liquid production for the Arenito and Carbonato reservoirs, and field for Approach 1.

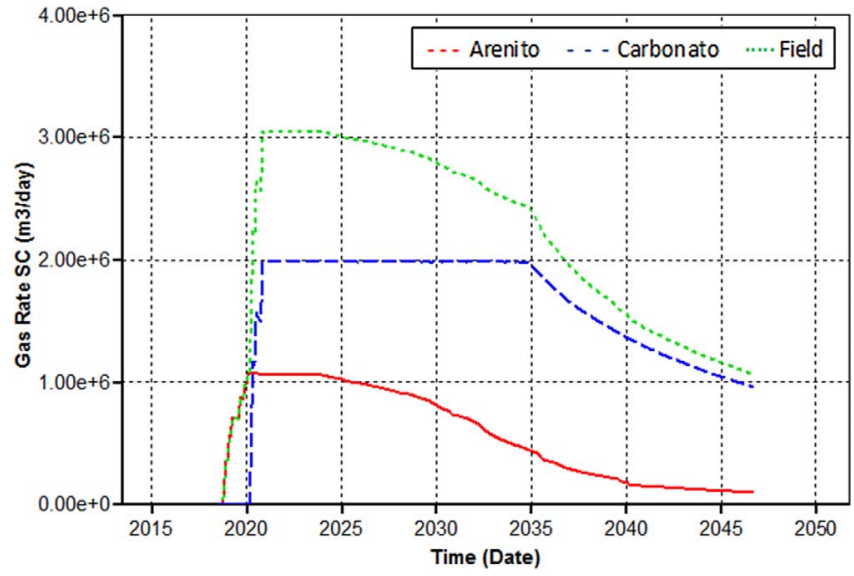

Fig. 7. Gas production for the Arenito and Carbonato reservoirs, and field for Approach 1.

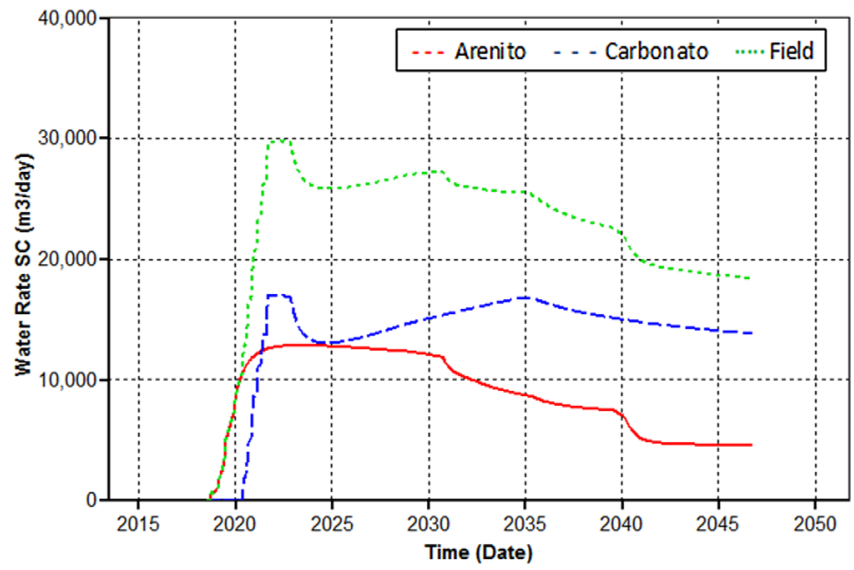

Fig. 8. Water injection for the Arenito and Carbonato reservoirs, and field for Approach 1. 
Table 2. Results obtained during the optimization procedures for Approach 2.

\begin{tabular}{lcccc}
\hline Step & Optimization & Results & Sims & dNPV (\%) \\
\hline 1 & Pipe diameter/gas lift & RI:6", FL:6", PC:5", QLIFT $=200000 \mathrm{~m}^{\mathbf{3}} /$ day & 8 & 2.7 \\
2 & Well number & Remove 1 well (Carbonato) & 4 & 0.5 \\
3 & Well placement & 8 iterations & 100 & 6.6 \\
4 & Pipe diameter/gas lift (2nd) & - & 1 & 0.0 \\
5 & Well number (2nd) & - & 2 & 0.0 \\
\hline
\end{tabular}

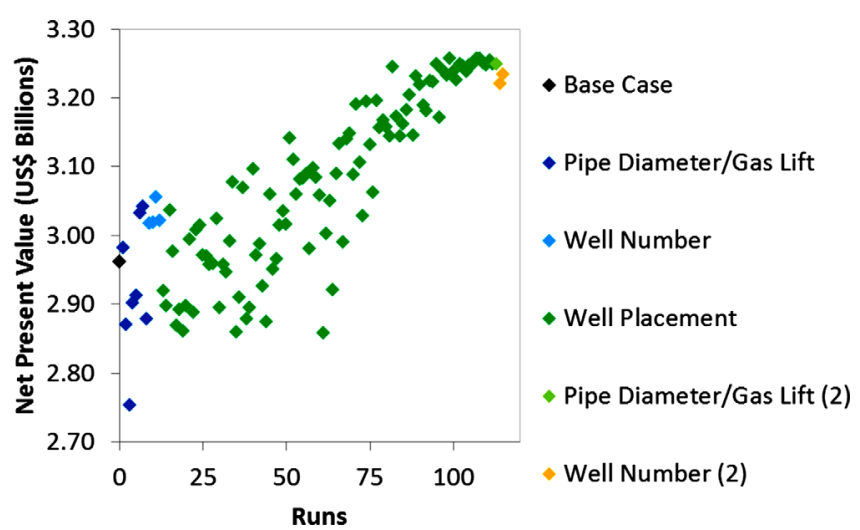

Fig. 9. Evolution of the NPV with the optimization procedure for Approach 2.

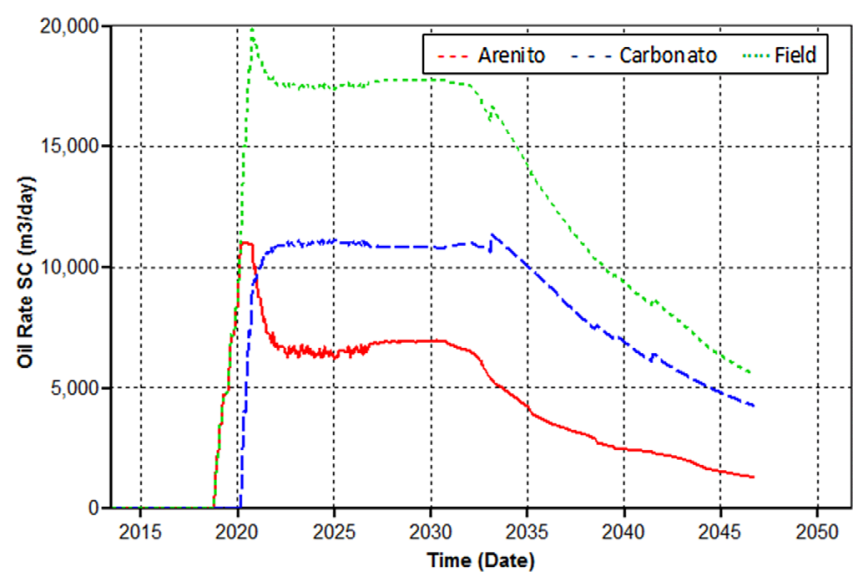

Fig. 10. Oil production for the Arenito and Carbonato reservoirs, and field for Approach 2.

restrictions for the Arenito reservoir. The platform limits were not reached in Approach 1.

Table 2 summarizes the results obtained during the optimization procedures for Approach 2. The optimization consumed 115 simulations and increased the base case NPV by $10 \%$. The optimization influenced by dynamic apportionment for platform capacities resulted in 1 well removed only.

Figure 9 shows the evolution of the NPV with the optimization procedure for Approach 2. The NPV objective function was more affected by well placement.

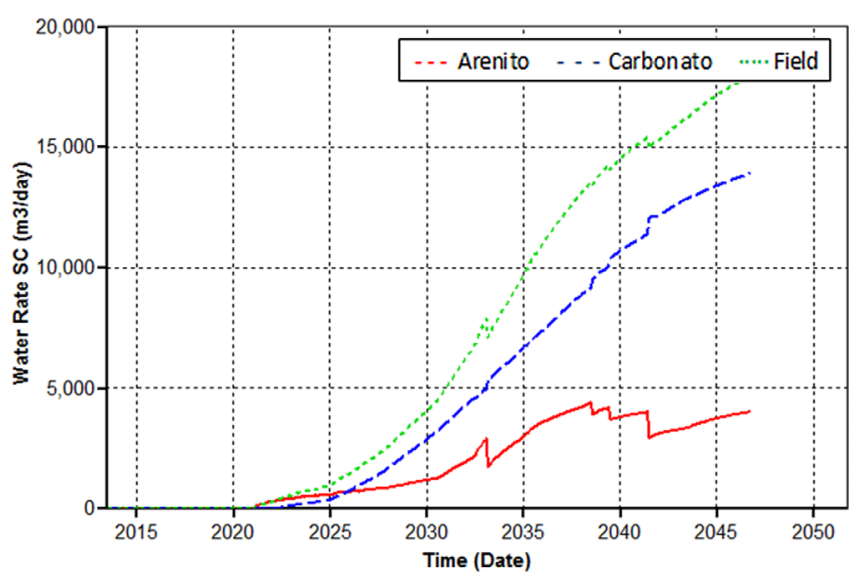

Fig. 11. Water production for the Arenito and Carbonato reservoirs, and field for Approach 2.

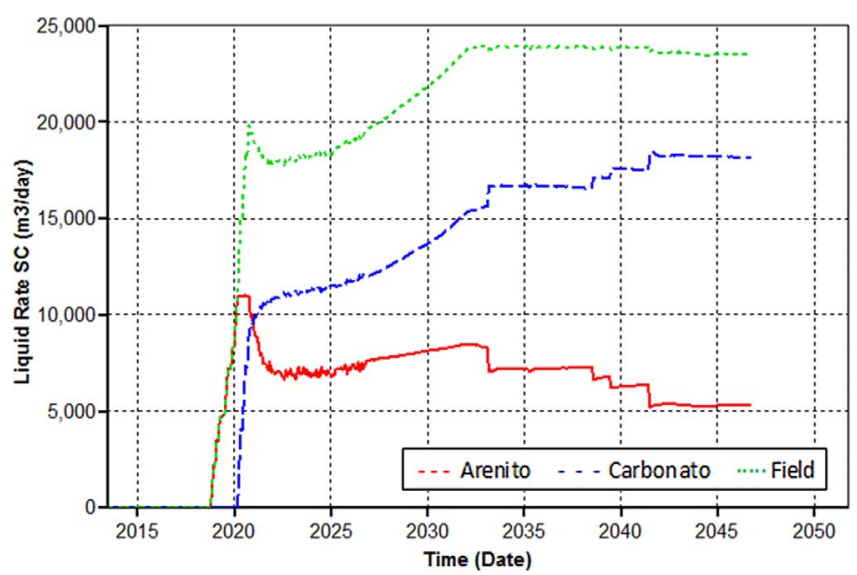

Fig. 12. Liquid production for the Arenito and Carbonato reservoirs, and field for Approach 2.

Figures 10-13 show oil, water, liquid, and gas production for the Arenito and Carbonato reservoirs, as well as total field production, respectively. Figure 14 shows water injection for the Arenito and Carbonato reservoirs, as well as total field injection. Due to the dynamic apportionment for each reservoir, there were platform rate restrictions for liquid and gas production in Approach 2.

Table 3 summarizes the results obtained during the optimization procedures for Approach 3. The optimization consumed 136 simulations and increased the base case NPV by $14 \%$. The results indicate that $100 \%$ of the platform 


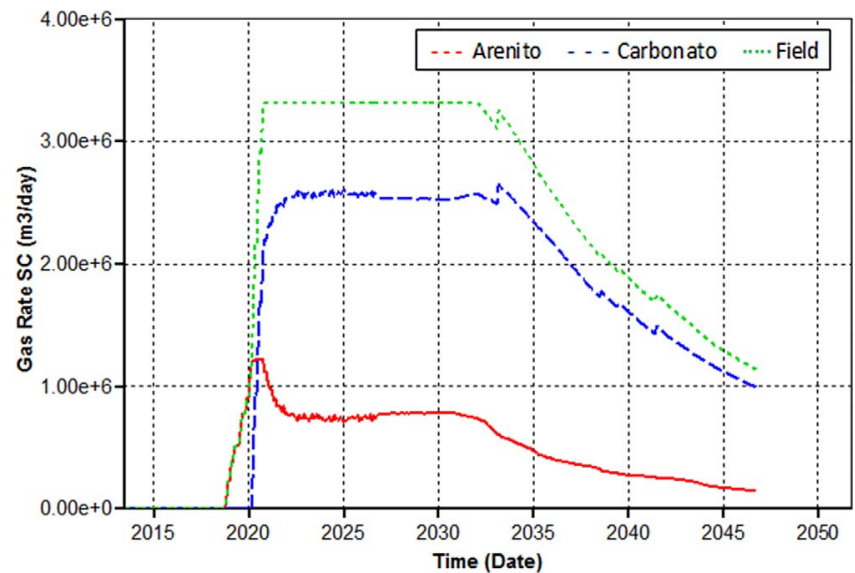

Fig. 13. Gas production for the Arenito and Carbonato reservoirs, and field for Approach 2.

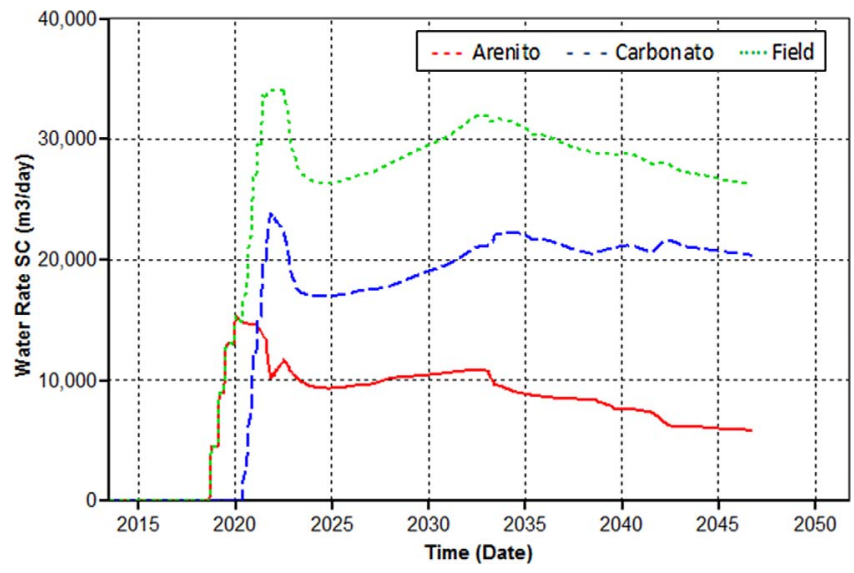

Fig. 14. Water injection for the Arenito and Carbonato reservoirs, and field for Approach 2.

Table 3. Results obtained during the optimization procedures for Approach 3.

\begin{tabular}{lcccc}
\hline Step & Optimization & Results & Sims & dNPV (\%) \\
\hline 1 & Weight WellPrior & $0 \% Q_{\mathrm{o}}, Q_{1}, Q_{\mathrm{g}}, Q_{\mathrm{w}}, 10 \% Q_{\mathrm{wi}}$ (Arenito) & 12 & 3.1 \\
2 & Pipe diameter/gas lift & $\mathrm{RI}: 6^{\prime \prime}, \mathrm{FL}: 6^{\prime \prime}, \mathrm{PC}: 5^{\prime \prime}$, QLIFT $=200000 \mathrm{~m}^{3} /$ day & 8 & 5.2 \\
3 & Well number & Remove 1 wells (1 Carbonato) & 4 & 0.1 \\
4 & Well placement & 8 iterations & 108 & 5.5 \\
5 & Weight WellPrior (2nd) & $0 \% Q_{\mathrm{o}}, Q_{1}, Q_{\mathrm{g}}, Q_{\mathrm{w}}, 10 \% Q_{\mathrm{wi}}$ (Arenito) & 1 & 0.0 \\
6 & Pipe diameter/gas lift (2nd) & - & 1 & 0.0 \\
7 & Well number (2nd) & - & 2 & 0.0 \\
\hline
\end{tabular}

production capacities and $90 \%$ of the platform injection capacity were weighted for Carbonate reservoir, and 1 well was removed.

Figure 15 shows the evolution of the NPV with the optimization procedure for Approach 3. The NPV objective function was more affected by well placement.

Figures 16-19 show oil, water, liquid, and gas production for the Arenito and Carbonato reservoirs, as well as total field production, respectively. Figure 20 shows water injection for the Arenito and Carbonato reservoirs, as well as total field injection. Due to the dynamic apportionment for each reservoir with specify weight, there were platform rate restrictions for liquid and gas production in Approach 3.

All approaches obtained the same production system specification: $\mathrm{RI}=6^{\prime \prime}, \mathrm{FL}=6^{\prime \prime}, \mathrm{PC}=5^{\prime \prime}$, and QLIFT $=$ $200000 \mathrm{~m}^{3} /$ day.

Table 4 summarizes the reservoir performance results from the optimization procedure for all approaches. The values that resulted in a Coefficient of Variation (CV) for all approaches above $10 \%$ were: $W_{p}$ for the Arenito and Carbonato reservoirs, and field; $W_{i}$ for the Carbonato reservoir; NPV for the Arenito reservoir; and number of wells for the Carbonato reservoir and field.

The computational time in Approach 1 for the decoupled runs was $57 \mathrm{~h}$. In Approaches 2 and 3 for explicit coupling runs, the computational times were $59 \mathrm{~h}$ and $67 \mathrm{~h}$ respectively.

\section{Discussion}

In optimization for all approaches, the step that most impacted the financial return was the allocation of wells, followed by the well number, well and gathering system diameters and gas lift configuration. The other steps had a minor influence on the production performance.

In this study we found significant differences between the values of $N_{p}\left(126-14210^{6} \mathrm{~m}^{3}\right), G_{p}\left(23-2610^{9} \mathrm{~m}^{3}\right)$, $W_{p}\left(48-7910^{6} \mathrm{~m}^{3}\right), W_{i}\left(231-28510^{6} \mathrm{~m}^{3}\right)$ and production strategy (23-32 wells). We observed a significant difference in field recovery, but not in NPV (3.3-3.4 US\$ Billion). The major differences were related to how the optimization process considered the Carbonato reservoir. The best well management prioritized oil production from the Sandstone reservoir at the expense of the Carbonato reservoir.

Approach 1 rendered the intermediate NPV compared with the other approaches. On the other hand, it provided the lowest oil recovery. We observed that the exclusion of several wells in the light oil field led to a good valuation of the project due to a reduction in the CAPEX and OPEX, even with these wells producing a fluid with better value. In addition, the platform had never reached its constraints.

Approach 2 provided the lower NPV performance in this case, and the intermediate oil recovery. We found that the well prioritization, based on flow, failed to capture the effects related to the different valuation of the fluids 
J.C. von Hohendorff Filho and D.J. Schiozer: Oil \& Gas Science and Technology - Rev. IFP Energies nouvelles 75, 70 (2020) 9

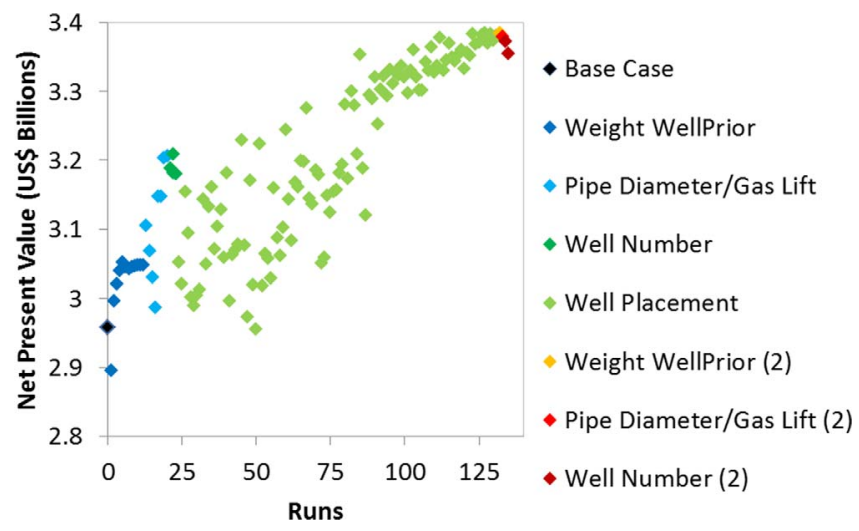

Fig. 15. Evolution of the NPV with the optimization procedure for Approach 3.

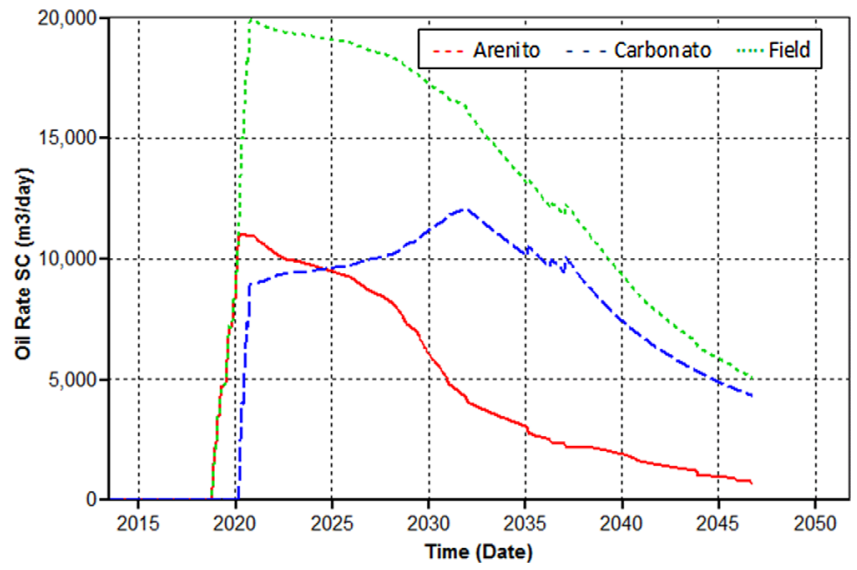

Fig. 16. Oil production for the Arenito and Carbonato reservoirs, and field for Approach 3.

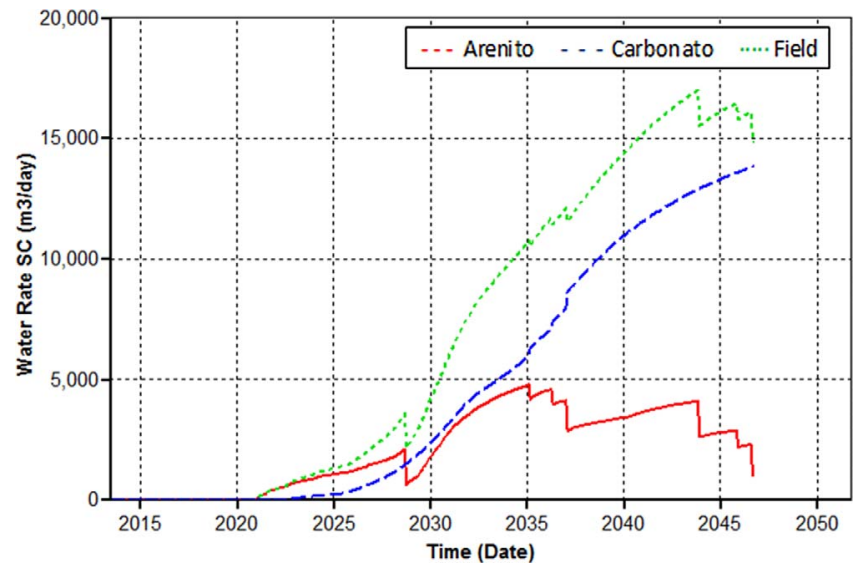

Fig. 17. Water production for the Arenito and Carbonato reservoirs, and field for Approach 3.

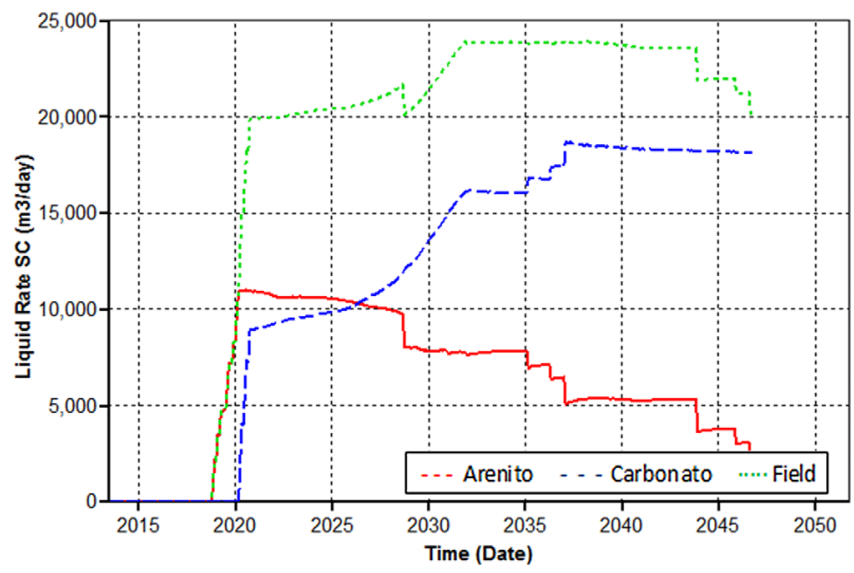

Fig. 18. Liquid production for the Arenito and Carbonato reservoirs, and field for Approach 3.

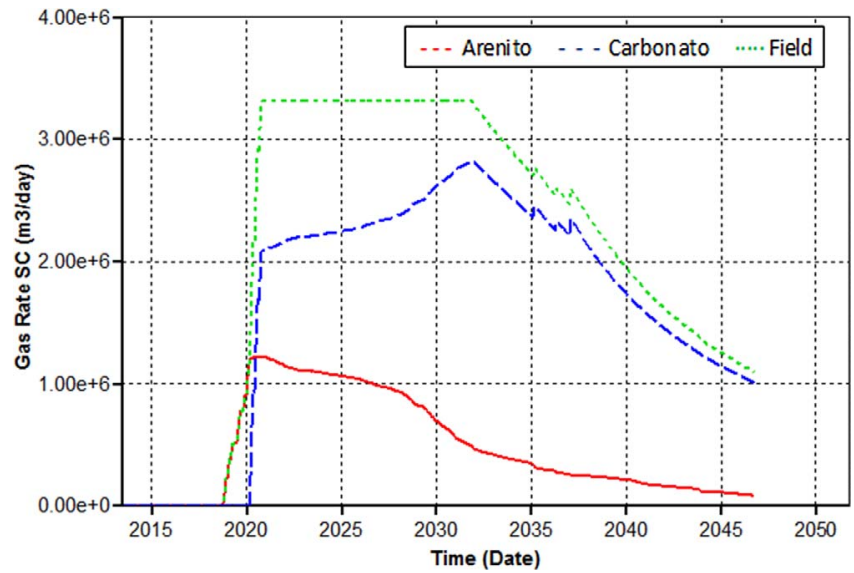

Fig. 19. Gas production for the Arenito and Carbonato reservoirs, and field for Approach 3.

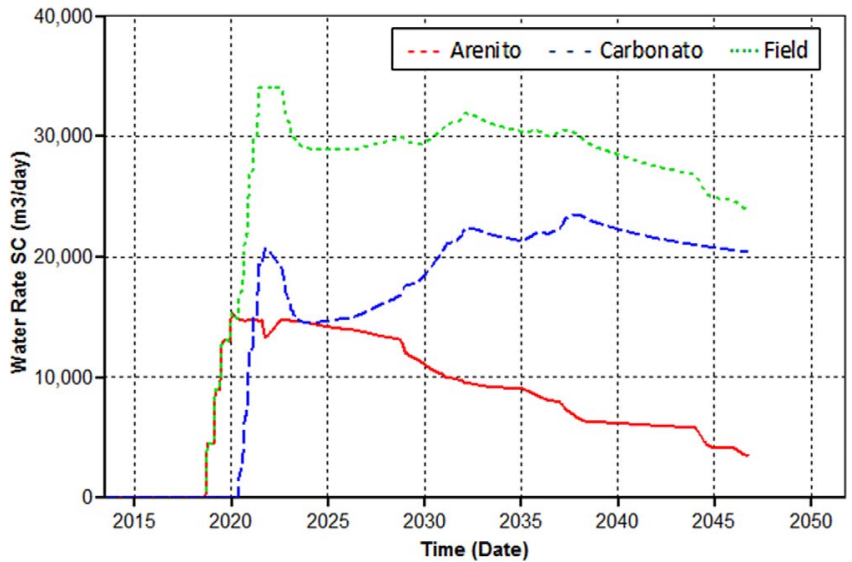

Fig. 20. Water injection for the Arenito and Carbonato reservoirs, and field for Approach 3. 
Table 4. Reservoir performance and objective function results from the optimization procedure for all approaches.

\begin{tabular}{lccccccc}
\hline Approach & Reservoir & $N_{p}\left(10^{6} \mathrm{~m}^{3}\right)$ & $G_{p}\left(10^{9} \mathrm{~m}^{3}\right)$ & $W_{p}\left(10^{6} \mathrm{~m}^{3}\right)$ & $W_{i}\left(10^{6} \mathrm{~m}^{3}\right)$ & NPV $\left(10^{9}\right.$ US\$) & Wells \\
\hline 1 & Arenito & 53.2 & 6.0 & 20.2 & 92.5 & 1.11 & 11 \\
& Carbonato & 72.9 & 17.0 & 27.8 & 138.1 & 2.25 & 12 \\
& Field & 126.0 & 23.0 & 48.1 & 230.6 & 3.36 & 23 \\
2 & Arenito & 54.5 & 6.2 & 24.4 & 98.4 & 0.68 & 13 \\
& Carbonato & 86.3 & 20.2 & 49.2 & 179.3 & 2.58 & 19 \\
3 & Field & 140.8 & 26.3 & 73.6 & 277.7 & 3.26 & 32 \\
& Arenito & 55.5 & 6.2 & 27.9 & 103.6 & 0.94 & 13 \\
& Carbonato & 86.0 & 20.1 & 51.3 & 181.5 & 2.44 & 19 \\
& Field & 141.5 & 26.3 & 79.2 & 285.0 & 3.38 & 32 \\
\hline
\end{tabular}

produced by the two reservoirs. The well management for gas restriction leads to uniform prioritization for gas flow between both reservoirs, and it did not take into account the type of oil, unlike Approach 1.

Approach 3, which handled the type of fluids similarly to Approach 1, provided the greater NPV and oil recovery than the other approaches. The weight for each reservoir applied to the well prioritization better captured the gains related to different valuation of the fluids produced by the two reservoirs. Dynamic prioritization with weights performed better results than the fixed apportionment for shared platform capacities.

The best well management prioritized oil production from the Sandstone reservoir, instead of the Carbonato reservoir, even with the Carbonato reservoir's oil price.

Well management based on gas flow with a weight applied to each reservoir provided a greater oil recovery $(+0.5 \%)$ and NPV $(+3.9 \%)$ than the simulation with production flow management based on gas flow only. Prioritization of well flows played a fundamental role in the performance of the integrated field, affecting the location of wells. Other optimization parameters had very similar values, indicating little impact on the optimization.

We observed that the control of G2 exerted an important influence on the economic return and production strategy selection, especially for multiple reservoirs with different fluids sharing a surface facility. This result serves as the basis for deciding, when it is necessary to perform a more thorough analysis of group G2.

We verified that the gas flow limit may not influence the selection of the production strategy for production poles. Number of wells optimization in production strategy can lead to a less restrictive scenario for platform capacity, even maintaining a relevant financial return (NPV), but with minor recovery factor.

For the case we studied subject to gas production limitation - the apportionment allocation rule, which prioritizes the restriction of wells with higher GOR - provided good financial return to the project, evidencing the need to define reservoir management strategy on a case-by-case basis. However, to apply the economic differences using weights for each reservoir for all the fluids increased NPV.
Approach 1 consumed in average $884 \mathrm{~s}$ for each integrated simulation time. Approaches 2 and 3 consumed higher values, in average $1847 \mathrm{~s}$ and $1773 \mathrm{~s}$ respectively. Even faster, Approach 1 optimization based in decoupled run couldn't reach a similar recovery result to Approaches 2 and 3 because it was not developed to manage different reservoir models separately, using only fixed flow-based apportionment.

\section{Conclusion}

A relevant impact on the choice of the optimization strategy of the management variables in the field development project was observed, changing well management routines for the studied approaches and affecting the oil recovery factor and production strategy.

We obtained different improvements in the project development optimization due to the anticipation of financial returns and CAPEX changes, due mainly from adequate well apportionment by different management algorithm.

We verified that the gas flow limit may not influence the selection of the production strategy for production poles. Number of wells optimization in production strategy can lead to a less restrictive scenario for platform capacity, even maintaining a relevant financial return, but with minor recovery factor.

Well management algorithms implemented in traditional simulators are not developed to prioritize different reservoir wells separately, especially if there are different economic conditions exemplified here by different valuation of produced fluids. This valuation should be taken into account in the short term optimization for wells.

\section{Supplementary material}

Supplementary material about production system model, reservoir simulation models, integrate simulation model, dates/mandatory times and premises is available at https://ogst.ifpenergiesnouvelles.fr/10.2516/ogst/2020064/ olm. 
Acknowledgments. This work was conducted with the support of Petrobras within the ANP R\&D tax as "commitment to research and development investments" and Energi Simulation through the Research Chairs at UNICAMP. The authors are grateful for the support of the Center of Petroleum Studies (CEPETRO UNICAMP), Department of Energy (DE-FEM-UNICAMP), Research Group in Reservoir Simulation and Management (UNISIM-UNICAMP) and CMG for software licenses.

\section{References}

1 Fraga C.T.C., Pinto A.C.C., Branco C.C.M., Pizarro J.O.S., Paulo C.A.S. (2015) Brazilian pre-salt: An impressive journey from plans and challenges to concrete results, in: Offshore Technology Conference, 4-7 May, Houston, Texas. https://doi.org/10.4043/25710-MS.

2 Huc A.Y. (2004) Petroleum in the South Atlantic, Oil Gas Sci. Technol. - Rev. IFP Energies nouvelles 59, 3, 243-253. https://doi.org/10.2516/ogst:2004017.

3 Kalaydjian F., Bourbiaux B. (2002) Integrated reservoir management: A powerful method to add value to companies' assets. A modern view of the EOR techniques, Oil Gas Sci. Technol - Rev. IFP Energies nouvelles 57, 3, 251-258. https://doi.org/10.2516/ogst:2002017.

4 Hegstad B.K., Saetrom J. (2014) Using multiple realizations from an integrated uncertainty analysis to make more robust decisions in field development, in: Abu Dhabi International Petroleum Exhibition and Conference, 10-13 November, Abu Dhabi, UAE. https://doi.org/10.2118/171831-ms.

5 Rahmawati S.D., Whitson C.H., Foss B., Kuntadi A. (2012) Integrated field operation and optimization, J. Pet. Sci. Eng. 81, 161-170. https://doi.org/10.1016/j.petrol.2011.12.027.

6 Kosmala A., Aanonsen S.I., Gajraj A., Biran V., Brusdal K., Stokkenes A., Torrens R. (2003) Coupling of a surface network with reservoir simulation, SPE Annual Technical Conference and Exhibition, 5-8 October, Denver, Colorado. https://doi.org/10.2118/84220-ms.

7 Rotondi M., Cominelli A., Di Giorgio C., Rossi R., Vignati E., Carati B. (2008) The benefits of integrated asset modelling: Lessons learned from field cases, in: Europec/EAGE Conference and Exhibition, 9-12 June, Rome, Italy. https://doi.org/ 10.2118/113831-ms.

8 Hiebert A.D., Khoshkbarchi M., Sammon P.H., Alves I.N., Rodrigues J., Belien A.J., Valvatne P.H. (2011) An advanced framework for simulating connected reservoirs, wells and production facilities, in: SPE Reservoir Simulation Symposium, 21-23 February, The Woodlands, Texas. https://doi. org $/ 10.2118 / 141012-\mathrm{ms}$.

9 Gaspar A.T.F.S., Barreto C.E.A.G., Schiozer D.J. (2016) Assisted process for design optimization of oil exploitation strategy, J. Pet. Sci. Eng. 146, 473-488. https://doi.org/ 10.1016/j.petrol.2016.05.042.

10 Santos D.R., Schiozer D.J. (2016) Impacto das Variáveis de Controle no Processo de Seleção da Estratégia de Produção sob Incertezas Durante a Fase de Desenvolvimento de Campos de Petróleo, in: Rio Oil \& Gas Expo and Conference, 24-27 October, Rio de Janeiro, Brazil.

11 Pinto M.A.S., Gildin E., Schiozer D.J. (2015) Short-term and long-term optimizations for reservoir management with intelligent wells, Society of Petroleum Engineers. https://doi.org/ 10.2118/177255-MS.
12 Azamipour V., Assareh M., Dehghani M.R., Mittermeir G.M. (2017) An efficient workflow for production allocation during water flooding, ASME J. Energy Resour. Technol. 139, 3, 032902. https://doi.org/10.1115/1.4034808.

13 Yue W., Yilin Wang J. (2015) Feasibility of waterflooding for a carbonate oil field through whole-field simulation studies, ASME J. Energy Resour. Technol. 137, 6, 064501. https://doi.org/10.1115/1.4030401.

14 Bento D.F., Schiozer D.J. (2010) The influence of the production lines pressure drop in the definition of the oilfield drainage strategy, in: SPE Latin American and Caribbean Petroleum Engineering Conference, 1-3 December, Lima, Peru. https://doi.org/10.2118/138259-ms.

15 Cotrim H.A., von Hohendorff Filho J.C., Schiozer D.J. (2011) Production optimization considering interaction between reservoirs and constrained surface facilities, in: SPE Reservoir Characterisation and Simulation Conference and Exhibition, 9-11 October, Abu Dhabi, UAE. https://doi. org / 10.2118/148334-ms.

16 Gramorelli F., Hohendorff Filho J.C.V., Schiozer D.J. (2018) Gerenciamento Integrado de Múltiplos Reservatórios Sujeitos a Restrições Operacionais e de Escoamento, in: Rio Oil \& Gas Conference, September 24-27, Rio de Janeiro, Brazil.

17 von Hohendorff Filho J.C., Schiozer D.J. (2018) Effect of reservoir and production system integration on field production strategy selection, Oil Gas Sci. Technol. - Rev. IFP Energies nouvelles 73, 44. https://doi.org/10.2516/ogst/2018042.

18 Gaspar A.T.F.S., Avansi G.D., Santos A.A.S., Hohendorff Filho J.C.V., Schiozer D.J. (2015) UNISIM-I-D: Benchmark studies for oil field development and production strategy selection, Int. J. Model. Simul. Petrol. Ind. 9, 47-55.

19 Avansi G.D., Schiozer D.J. (2015) UNISIM-I: Synthetic model for reservoir development and management applications, Int. J. Model. Simul. Petrol. Ind. 9, 1, 21-30.

20 Correia M., Hohendorff J., Gaspar A.T.F.S., Schiozer D. (2015) UNISIM-II-D: Benchmark case proposal based on a carbonate reservoir, Society of Petroleum Engineers. https://doi.org/10.2118/177140-MS.

21 Victorino I.R.S., Hohendorff Filho J.C.V., Schiozer D.J. (2016) Sensibility analysis of production system parameters for integrated simulation of reservoir and production systems, in: Rio Oil \& Gas Conference, 24-27 October, Rio de Janeiro, Brazil.

22 Schiozer D.J., Santos A.A.S., Drumond P.S. (2015) Integrated model based decision analysis in twelve steps applied to petroleum fields development and management, in: EUROPEC 2015, 1-4 June, Madrid, Spain. https://doi. org $/ 10.2118 / 174370-\mathrm{ms}$.

23 Standing M.B. (1947, January 1) A pressure-volumetemperature correlation for mixtures of California oils and gases, American Petroleum Institute.

24 Brill J.P., Beggs H.D. (1991) Two-phase flow in pipes, 6th edn., Third Printing. University of Tulsa, Tulsa, Oklahoma.

25 Siavashi M., Yazdani M. (2018) A comparative study of genetic and particle swarm optimization algorithms and their hybrid method in water flooding optimization, ASME J. Energy Resour. Technol. 140, 10, 102903. https://doi.org/ 10.1115/1.4040059.

26 Campozana F.P., Dos Santos R.L., Madeira M.G., Sousa S. H.G., Spinola M. (2008) Optimization of surface network and platform location using a next generation reservoir simulator coupled with an integrated asset optimizer - an application to an offshore deep water oil field in Brazil, International 
Petroleum Technology Conference, 3-5 December, Kuala Lumpur, Malaysia. https://doi.org/10.2523/iptc-12500-ms.

27 Sukarno P., Saepudin D., Dewi S., Soewono E., Sidarto K.A., Gunawan A.Y. (2009) Optimization of gas injection allocation in a dual gas lift well system, ASME J. Energy Resour. Technol. 131, 3, 033101. https://doi.org/10.1115/1.3185345.

28 Abellan A., Noetinger B. (2010) Optimizing subsurface field data acquisition using information theory, Math. Geosci. 42, 6, 603-630. https://doi.org/10.1007/s11004-010-9285-6.

29 Bouzarkouna Z., Ding D.Y., Auger A. (2011) Well placement optimization with the covariance matrix adaptation evolution strategy and meta-models, Comput. Geosci. 16, 1, 75-92. https://doi.org/10.1007/s10596-011-9254-2.
30 Bouzarkouna Z., Ding D.Y., Auger A. (2013) Partially separated metamodels with evolution strategies for wellplacement optimization, SPE J. 18, 6, 1003-1011. https://doi.org/10.2118/143292-pa.

31 von Hohendorff Filho J.C., Maschio C., Schiozer D.J. (2016) Production strategy optimization based on iterative discrete Latin hypercube, J. Braz. Soc. Mech. Sci. Eng. 38, 2473-2480. https://doi.org/10.1007/s40430-016-0511-0.

32 von Hohendorff Filho J.C., Schiozer D.J. (2018) Correcting inflow performance relationship curves for explicitly coupling reservoir simulations and production systems simulations, ASME J. Energy Resour. Technol. 140, 3, 032006. https://doi.org/10.1115/1.4038045. 